\title{
Selective Inhibitors Differentially Affect Cyclooxygenase-Dependent Pial Arteriolar Responses in Newborn Pigs
}

\author{
FERENC DOMOKI, KRISZTINA NAGY, PÉTER TEMESVÁRI, AND FERENC BARI \\ Department of Physiology, Faculty of Medicine [F.D., K.N., F.B.], University of Szeged, Szeged, Dóm tér \\ 10. H-6720, Hungary; Department of Pediatrics [P.T.], University Teaching Hospital, Kecskemét, P.O. \\ Box 149, H-6001, Hungary
}

\begin{abstract}
ABST
Cyclooxygenase (COX)-derived prostanoids play an impor-
tant role in the cerebrovascular control of newborns. In humans
and in the widely accepted model of piglets, both the COX-1 and
the COX-2 isoforms are expressed in cerebral arteries. However,
the involvement of these isoforms in cerebrovascular control is
unknown. Therefore we tested if specific inhibitors of COX-1
and/or COX-2 would differentially affect pial arteriolar responses
to COX-dependent stimuli in piglets. Anesthetized, ventilated
piglets $(n=35)$ were equipped with a closed cranial window,
and changes in pial arteriolar diameters (baseline $\sim 100 \mu \mathrm{m})$ to
hypercapnia (ventilation with $5-10 \% \mathrm{CO}, 21 \% \mathrm{O}_{2}$, balance $\mathrm{N}_{2}$ ),
arterial hypotension ( 40 mm $\mathrm{Hg} \mathrm{MABP}$ achieved by blood
withdrawal), and Ach (Ach, $10-100 \mu \mathrm{M})$ were determined via
intravital microscopy. Arteriolar responses were repeatedly
tested 15 min after IV administration of selective COX-1 and
COX-2 inhibitors SC-560 and $\mathrm{NS}-398(1-1 \mathrm{mg} / \mathrm{kg})$, and nonse-
lective inhibitors indomethacin $(0.3-1 \mathrm{mg} / \mathrm{kg})$, acetaminophen
(30 mg/kg), and ibuprofen $(30 \mathrm{mg} / \mathrm{kg}) . \mathrm{Hypercapnia}$ resulted in
concentration-dependent, reversible, $(\sim 20-40 \%)$ increases in
pial arteriolar diameters that were unaffected by NS-398, SC-
\end{abstract}
Cyclooxygenase $(\mathrm{COX})$ is the rate-limiting enzyme of prostanoid biosynthesis and ubiquitously found in most cells including microvascular endothelium and vascular smooth muscle (VSM). COX has two major isoforms coded by different genes (COX-1 and COX-2) that can now be targeted with selective inhibitors. More molecular variants exist as suggested by the recent description of a splice-variant of $\mathrm{COX}-1$, putatively named COX-3 (1). In the piglet cerebral arteries, both

Received May 24, 2004; accepted September 27, 2004.

Correspondence: Ferenc Domoki, M.D. Ph.D., Department of Physiology, Faculty of Medicine, University of Szeged, Szeged, Dóm tér 10, Hungary; H-6720; E-mail: domoki@phys.szote.u-szeged.hu

Ferenc Domoki is supported by the Magyary Zoltán Postdoctoral Fellowship. This study was supported by grants from the National Scientific Research Fund of Hungary (OTKA, F-043101 and T-046531) and the Hungarian Ministry of Health (ETT 6003/2001).

DOI: 10.1203/01.PDR.0000161415.62776.0A
560 , acetaminophen and ibuprofen. In contrast, $0.3 \mathrm{mg} / \mathrm{kg}$ indomethacin significantly reduced, $1 \mathrm{mg} / \mathrm{kg}$ virtually abolished the vasodilation. Arterial hypotension elicited $(\sim 15-20 \%)$ vasodilation that was similarly reduced by NS-398 and indomethacin but was unaltered by SC-560. Ach dose-dependently constricted pial arterioles. This response was similarly attenuated by NS-398, indomethacin, and ibuprofen, but left intact by SC-560. We conclude that the assessed COX-dependent vascular reactions appear to depend largely on COX-2 activity. However, hypercapnia-induced vasodilation was found indomethacin-sensitive instead of a COX-dependent response in the piglet. (Pediatr Res 57: 853-857, 2005)

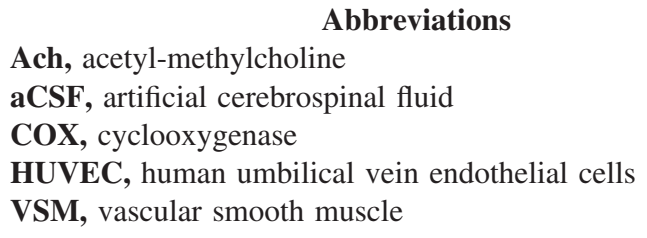

COX-1 and COX-2 mRNA-s are expressed with COX-2 being the dominant constitutive isoform (2).

COX-activity plays opposing roles in the cerebral circulation under physiologic and pathologic conditions. In normoxia, COX-derived metabolites play an important role in the control of VSM in many cerebrovascular regulatory pathways (3). In contrast, uncontrolled COX-activity under hypoxic/ischemic stress may be an ample source of superoxide anions and proinflammatory prostanoids involved in cellular injury and cell death $(4,5)$. In fact, COX-inhibitors have pronounced neuroprotective effects in many neonatal and adult experimental models of hypoxia and stroke. In the piglet, the direct protective effect of $\mathrm{COX}$-inhibitors on neurons after ischemic stress appears to be mediated by COX-2 (6). However, COX inhibitors may also indirectly produce neuroprotection by preserving the ischemia-sensitive elements of cerebrovascular reactivity. Indeed, indomethacin prevented the postischemic 
attenuation of cerebrovascular reactivity to numerous stimuli that dilated pial arterioles through COX-independent pathways $(7,8)$. However, a number of ischemia-sensitive vasodilatory mechanisms are themselves COX-dependent, thus COXinhibitors given for neuroprotection should simultaneously impair cerebrovascular control to some extent. Unfortunately the selective contribution of COX-1 and/or COX-2 activity to different ischemia-sensitive, COX-dependent cerebral arteriolar responses is currently unknown. The potential clinical application of COX-inhibitors as a neuroprotective strategy however, warrants this information.

The present study investigated whether selective inhibitors of COX-1 (SC-560) and COX-2 (NS-398) would differentially affect pial arteriolar responses to the following COXdependent stimuli compared with the effect of indomethacin: 1) hypercapnia (9), and 2) arterial hypotension-induced vasodilation (10), as well as 3) acetyl-methylcholine (Ach)-induced vasoconstriction $(11,12)$. The comparison of combined COX-1 and COX-2 inhibition with the effect of indomethacin generated further experiments that yielded new data on the mechanism of hypercapnia-induced vasodilation.

\section{MATERIALS AND METHODS}

\footnotetext{
Animals. Newborn piglets of either sex ( $<24 \mathrm{~h}$ old, body weight $1-2 \mathrm{~kg}, n$ $=35$ ) were used. All procedures were approved by the Institution Animal Care and Use Committee. The animals were anesthetized with sodium thiopental (30-40 mg/kg ip, Biochemie, Vienna, Austria) followed by IV injection of $\alpha$-chloralose (40 mg/kg, Sigma Chemical Co., St. Louis, MO). Supplemental doses of $\alpha$-chloralose were given to maintain a stable level of anesthesia. The right femoral artery and vein were catheterized to record blood pressure and to administer drugs and fluids, respectively. The piglets were intubated via tracheotomy and artificially ventilated with room air. The ventilation rate $(\sim 20 / \mathrm{min})$ and tidal volume $(\sim 20 \mathrm{~mL})$ were adjusted to maintain arterial blood gas values and $\mathrm{pH}$ in the physiologic range. Body temperature was maintained at $37-38^{\circ} \mathrm{C}$ by a water-circulating heating pad. Body temperature, arterial $\mathrm{pH}$ and blood gases were kept in the normal ranges, and did not vary significantly among different groups. For instance, in Group 2 the values were $37.4 \pm 0.1^{\circ} \mathrm{C}, \mathrm{pH}=7.48 \pm 0.02, \mathrm{pCO}_{2}=32.7 \pm 1.0 \mathrm{~mm} \mathrm{Hg}, \mathrm{pO}_{2}=86.7$ $\pm 5 \mathrm{~mm} \mathrm{Hg}$.

The animals were equipped with a closed cranial window as described (2). The cranial window was filled with artificial cerebrospinal fluid (aCSF) warmed to $37^{\circ} \mathrm{C}$ and equilibrated with $6 \% \mathrm{O}_{2}$ and $6.5 \% \mathrm{CO}_{2}$ in balance $\mathrm{N}_{2}$ to give $\mathrm{pH}=7.33, \mathrm{pCO}_{2}=46 \mathrm{~mm} \mathrm{Hg}$, and $\mathrm{pO}_{2}=43 \mathrm{~mm} \mathrm{Hg}$. The pial circulation was visualized using an operating microscope (Wild, Switzerland) equipped with a CCD camera (A. Krüss, Germany) connected to a TV monitor (Panasonic, Japan). In each experiment, a pial arteriole having an approximately $100 \mu \mathrm{m}$ diameter was selected. Pial arteriolar diameters were then determined with a video microscaler. Following surgery the cranial window was perfused with aCSF until a stable arteriolar baseline diameter was obtained. At the end of the experiments the animals were killed while anesthetized with an IV bolus of saturated $\mathrm{KCl}$ solution.

Assessment of cerebrovascular reactivity. After obtaining stable baseline arteriolar diameters, we examined the responses of cerebral arterioles to hypercapnia, arterial hypotension, and Ach before and $15 \mathrm{~min}$ after IV administration of various COX inhibitors (see study groups for details). Arteriolar diameters were measured continuously for 5-7 min to hypercapnia and Ach, and for 3 min to hypotension. These periods resulted in maximal and stable increases in vascular caliber, and ensured that autonomic reflexes (for instance the weak baroreceptor response (3)) or short-term changes in MABP would not affect arteriolar diameters. After each stimulus the window was flushed with aCSF and the arteriolar diameters were allowed to return to baseline values before the administration of COX inhibitors. Graded hypercapnia was elicited by ventilating the animal with a gas mixture containing 5 and $10 \% \mathrm{CO}_{2}, 21 \% \mathrm{O}_{2}$, balance $\mathrm{N}_{2}$. Arterial hypotension (MABP $=40 \mathrm{~mm}$ $\mathrm{Hg}$ ) was evoked by reversible removal of arterial blood to a heparinized syringe. Ach was dissolved in aCSF $(10-100 \mu \mathrm{M})$ and applied to the pial surface through the injectible ports of the cranial window.
}

Drugs. Ach (Sigma Chemical Co.) was dissolved in aCSF. NS-398 (Sigma Chemical Co.) and SC-560 (Cayman Chemicals, Ann Arbor, MI) were dissolved in DMSO $(10 \mathrm{mg} / \mathrm{mL})$. Indomethacin (Merck \& Co, Whitehouse Station, NJ) and ibuprofen (Sigma Chemical Co.) were dissolved in saline (2 $\mathrm{mg} / \mathrm{mL}$ and $30 \mathrm{mg} / \mathrm{mL}$, respectively). Acetaminophen (Sigma Chemical Co.) was dissolved in ethanol $(50 \mathrm{mg} / \mathrm{mL})$.

Study groups. Group $1(n=5)$ : Arteriolar responses to hypercapnia $(10 \%$ $\mathrm{CO}_{2}$ ) and hypotension were recorded before and $15 \mathrm{~min}$ after administration of selective COX-2 inhibitor NS-398 (1 mg/kg, IV). The stimuli then were repeated once more $15 \mathrm{~min}$ after indomethacin treatment $(1 \mathrm{mg} / \mathrm{kg}, \mathrm{IV})$.

Group $2(n=5)$ : Arteriolar responses to hypercapnia $\left(10 \% \mathrm{CO}_{2}\right)$ and hypotension were recorded before and $15 \mathrm{~min}$ after administration of selective COX-1 inhibitor SC-560 (1 mg/kg, IV). The stimuli then were repeated once more 15 min after combined administration of SC-560 and NS-398 (1-1 $\mathrm{mg} / \mathrm{kg}, \mathrm{IV})$.

Group $3(n=6)$ : Arteriolar responses to hypercapnia $\left(5-10 \% \mathrm{CO}_{2}\right)$ were measured before and $15 \mathrm{~min}$ after administration of acetaminophen $(30 \mathrm{mg} / \mathrm{kg}$, IV).

Group $4(n=5)$ : Arteriolar responses to hypercapnia $\left(5-10 \% \mathrm{CO}_{2}\right)$ were recorded before and $15 \mathrm{~min}$ after administration of ibuprofen $(30 \mathrm{mg} / \mathrm{kg}, \mathrm{IV})$. The stimulus was then repeated once more $15 \mathrm{~min}$ after a low dose of indomethacin $(0.3 \mathrm{mg} / \mathrm{kg}, \mathrm{IV})$.

Group $5(n=6)$ : Arteriolar responses to Ach were measured before and 15 min after NS-398 $(1 \mathrm{mg} / \mathrm{kg}, \mathrm{IV})$. The stimulus then was repeated once more 15 min after indomethacin treatment $(1 \mathrm{mg} / \mathrm{kg}, \mathrm{IV})$.

Group $6(n=8)$ : Arteriolar responses to Ach were measured before and 15 $\min$ after SC-560 $(1 \mathrm{mg} / \mathrm{kg}$, IV). The stimulus then was repeated once more 15 min after ibuprofen treatment $(30 \mathrm{mg} / \mathrm{kg}, \mathrm{IV})$.

Statistics. Data are expressed as mean \pm SD. Pial arteriolar diameter data were analyzed using repeated measures analysis of variance, followed by pairwise comparisons using the Student-Newman-Keuls test where appropriate (SigmaStat, Jandel Co., San Rafael, CA). P values of $<0.05$ were considered statistically significant.

\section{RESULTS}

Effect of COX-inhibitors on hypercapnia-induced vasodilation. Hypercapnia significantly elevated arterial $\mathrm{pCO}_{2}$ levels with simultaneous reductions in arterial $\mathrm{pH}$ during repeated challenges in all experimental groups. For instance, in Group 3, $5 \%$ and $10 \% \mathrm{CO}_{2}$ elevated $\mathrm{pCO}_{2}$ levels from $35.9 \pm 2.9$ to $47.2 \pm 1.8$ and $66.2 \pm 2.5 \mathrm{~mm} \mathrm{Hg}$, and from $33.2 \pm 4.8$ to 46.9 \pm 1.2 and $63.8 \pm 1.6 \mathrm{~mm} \mathrm{Hg}$, before and after drug treatment, respectively. At the same time arterial $\mathrm{pH}$ was reduced from $7.41 \pm 0.04$ to $7.27 \pm 0.03$ and $7.14 \pm 0.03$, and from $7.37 \pm$ 0.03 to $7.26 \pm 0.03$ and $7.14 \pm 0.03$ before and after drug treatment, respectively. Hypercapnia also resulted in reversible, concentration-dependent pial arteriolar vasodilation (Fig. 1). In Group 1, NS-398 did not inhibit the vasodilation (Fig. 1A). In Group 2, SC-560 also had no effect (Fig. 1B). In Group 1, administration of indomethacin after NS-398 virtually abolished the dilatory response (Fig. 1A). In Group 2, however, combined administration of the two selective drugs only resulted in moderate decrease in vascular reactivity, the remaining response was still much larger than after indomethacin (Fig. 1B). In Group 3, acetaminophen and in Group 4, ibuprofen administration also failed to alter arteriolar responses to hypercapnia, similarly to the selective inhibitors (Fig. 1C-D). Interestingly, in Group 4, a low dose of indomethacin $(0.3 \mathrm{mg} / \mathrm{kg})$ given after ibuprofen could still attenuate hypercapnia-induced vasodilation by $\sim 50 \%$ (Fig. $1 D$ ).

Effect of COX-inhibitors on hypotension-induced vasodilation. Lowering MABP to $40 \mathrm{~mm} \mathrm{Hg}$ resulted in reversible arteriolar dilation (Fig. 2). In Group 1, NS-398 treatment significantly attenuated vasodilation, and indomethacin could not further inhibit vasodilation to hypotension after COX-2 inhibition by NS-398 (Fig. 2A). In contrast, SC-560 alone 


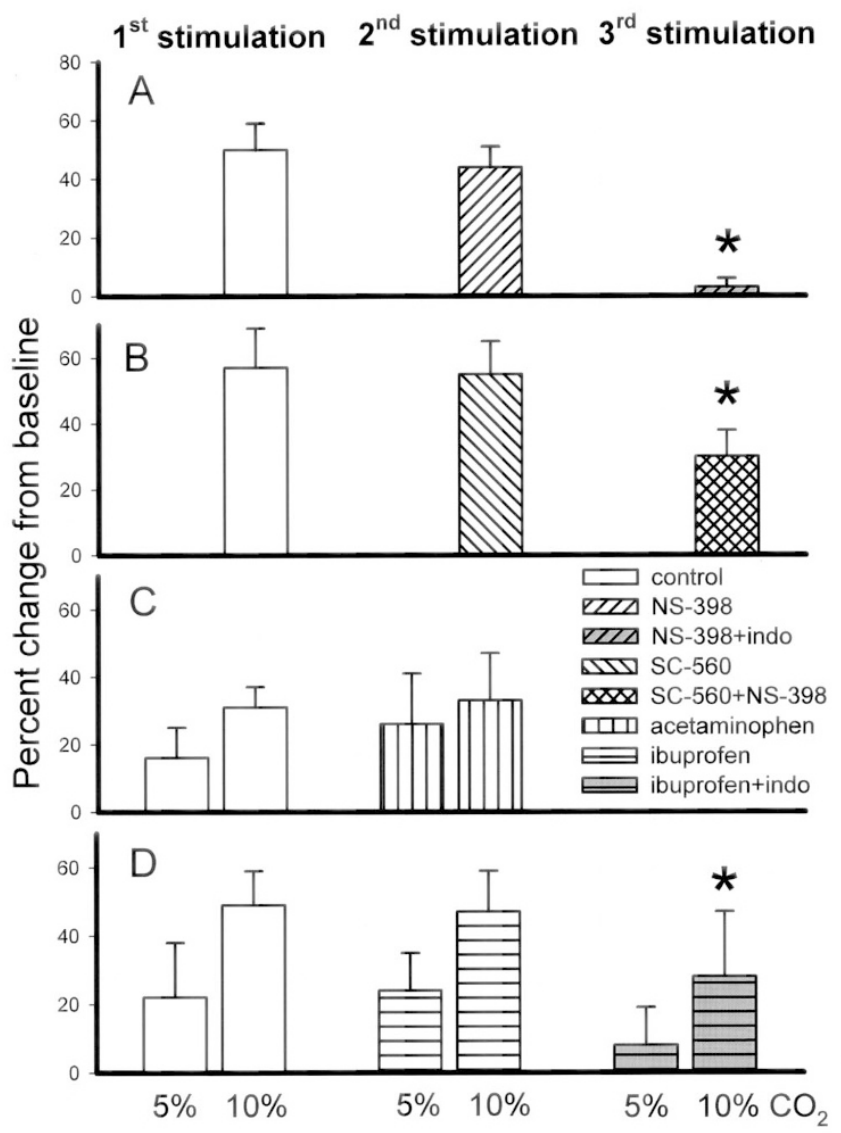

Figure 1. Effect of cyclooxygenase (COX) inhibitors on pial arteriolar dilations to hypercapnia induced by $5-10 \% \mathrm{CO}_{2}$ ventilation. First, control vascular reactivity to hypercapnia was recorded (white bars). After each stimulus, pial arteriolar diameters were allowed to return to baseline values. COX inhibitors were then administered by IV 15 min before the induction of repeated stimulation with hypercapnia. Neither the selective COX-2 inhibitor NS-398 (1 mg/kg, Graph A, slashed bar) nor the selective COX-1 inhibitor SC-560 (1 mg/kg Graph B, backslashed bar) alone altered arteriolar responses to hypercapnia. The combined administration of the selective drugs (1-1 $\mathrm{mg} / \mathrm{kg}$, Graph B, hatched bar) resulted in moderate, but significant reduction of cerebrovascular reactivity, whereas addition of indomethacin (indo, $1 \mathrm{mg} / \mathrm{kg}$, Graph A, slashed gray bar) virtually abolished the response. Interestingly, the nonselective COX-inhibitors like acetaminophen $(30 \mathrm{mg} / \mathrm{kg}$, Graph C, vertical striped bars), or ibuprofen (30 mg/kg, Graph D, horizontal striped bars) left hypercapnia-induced pial arteriolar dilations intact. Further, after total COXinhibition by ibuprofen, a small dose of indomethacin $(0.3 \mathrm{mg} / \mathrm{kg})$ could still significantly diminish vascular reactivity (Graph $\mathrm{D}$, horizontal striped gray bars). $* p<0.05$ significantly smaller response than the control response before treatment. Graphs A-D corresponds to experimental groups $1-4, n=5,5,6$, and 5 , respectively.

unaltered hypotension induced vasodilation in Group 2 (Fig. $2 B$ ), but consequent administration of NS-398 was able to significantly attenuate the response (Fig. $2 B$ ).

Effect of COX-inhibitors on Ach-induced vasoconstriction. Ach elicited dose-dependent vasoconstriction (Fig. 3). In Group 5, NS-398 significantly attenuated Ach-induced vasoconstriction, but subsequent administration of indomethacin had no further inhibitory effect (Fig. 3A). In Group 6, however, SC-560 had no inhibitory effect on Ach-induced vasoconstriction, whereas ibuprofen was able to reduce this vascular response similarly to NS-398 or indomethacin (Fig. 3B).

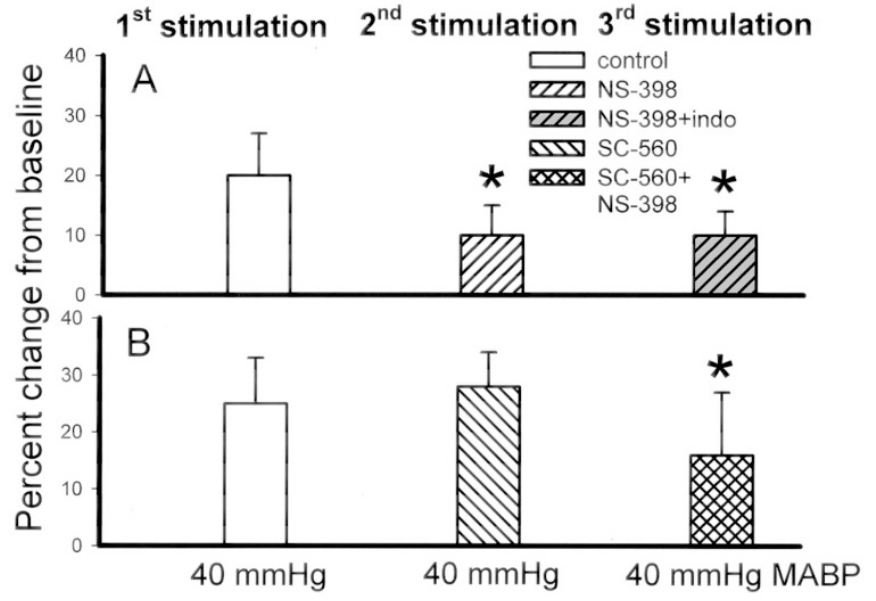

Figure 2. Effect of cyclooxygenase (COX) inhibitors on pial arteriolar dilations to hypotension $(40 \mathrm{~mm} \mathrm{Hg})$ induced by reversible venous blood withdrawal. First, control vascular response to hypercapnia was determined (white bars). After each stimulus, pial arteriolar diameters were allowed to return to baseline values. COX inhibitors were then administered by IV $15 \mathrm{~min}$ before repeated stimulation with hypotension. The selective COX-2 inhibitor NS-398 (1 mg/kg, Graph A, slashed bar) significantly reduced the arteriolar response to hypotension, and addition of indomethacin (indo, $1 \mathrm{mg} / \mathrm{kg}$, Graph A, slashed gray bar) had no further inhibitory effect. In contrast, the selective COX-1 inhibitor SC-560 (1 mg/kg Graph B, backslashed bar) alone failed to alter vasodilation to hypotension. However, the addition of NS-398 to SC-560 (1-1 mg/kg, Graph B, hatched bar) resulted in significant attenuation of the response, similarly to the effect of NS-398 alone. ${ }^{*} p<0.05$ significantly smaller response than the control response before treatment. Graphs A-B correspond to experimental groups $1-2, n=5$ and 5 , respectively.

\section{DISCUSSION}

The major findings of the present study are the following: 1) hypotension-induced vasodilation, 2) Ach-induced vasoconstriction are sensitive to COX-2 inhibition by NS-398, and 3) nonselective COX inhibitors (indomethacin, ibuprofen) could not further attenuate vascular reactivity to these stimuli (4). In contrast, these vascular responses remained unchanged after COX-1 inhibition by SC-560 (5). We confirmed that hypercapnia-induced arteriolar vasodilation is extremely indomethacin-sensitive, but we found this effect of indomethacin is unlikely to be related to inhibition of COX.

The present findings support the concept that COXdependent cerebrovascular responses are mainly dependent on cerebrovascular COX-2 activity. Our present in vivo results using COX isoform-selective pharmacological tools are in accordance with the dominant, strong expression of COX-2 in the piglet brain and cerebral arteries, especially the microvascular endothelium (2), and the COX-2 dependency of in vivo cerebrovascular prostanoid production in piglets (13). The assessed COX-dependent responses mainly require COXproducts from endothelial cells, since selective endothelial injury diminishes the responsiveness to these stimuli $(14,15)$. Indeed, freshly isolated or cultured endothelial cells from piglet brains or autopsy specimens of neonatal human cerebral cortex have also been found to produce prostanoids mainly via the activity of COX-2 (16,17).

Previously, proposed COX-dependent responses must have fulfilled two criteria: 1) the level of endogenous prostanoids in 


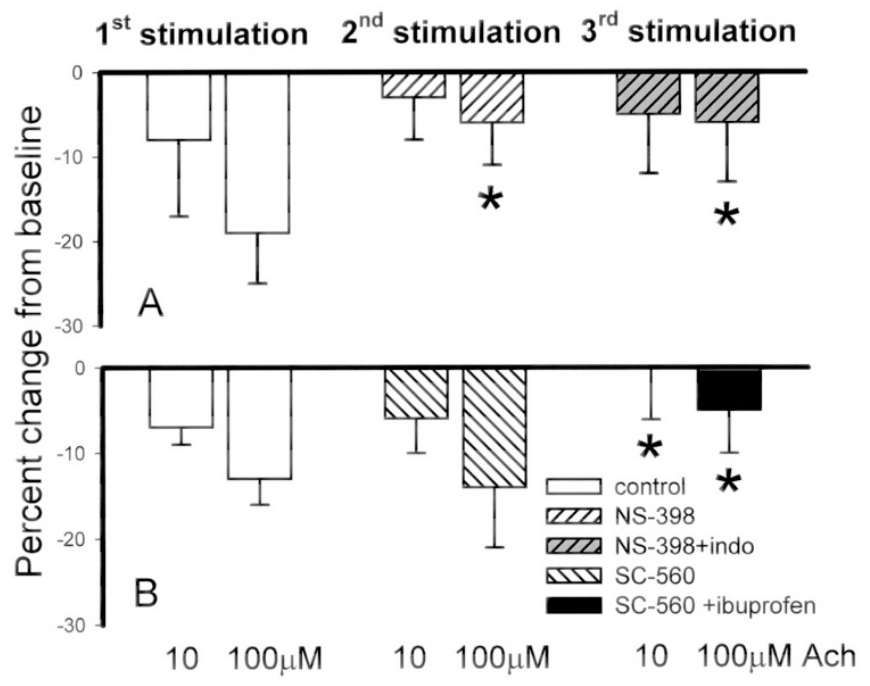

Figure 3. Effect of cyclooxygenase (COX) inhibitors on dose-dependent pial arteriolar constrictions to local, pial administration of Ach (Ach, 10-100 $\mu \mathrm{M}$ ). First, control vascular response to Ach was determined (white bars). After each stimulus, pial arteriolar diameters were allowed to return to baseline values. COX inhibitors were then administered by IV $15 \mathrm{~min}$ before repeated stimulation with Ach. The selective COX-2 inhibitor NS-398 (1 mg/kg, Graph A, slashed bars) but not the COX-1 inhibitor SC-560 (1 mg/kg, Graph B, backslashed bars) reduced arteriolar responses to Ach. Subsequent administration of indomethacin (indo, Graph A, slashed gray bar) did not have further inhibitory effect, whereas ibuprofen administration after COX-1 inhibition by SC-560 (30 mg/kg, Graph B, black bars) successfully diminished the vasoconstriction. ${ }^{*} p<0.05$ significantly smaller response than the control response before treatment. Graphs A-B correspond to experimental groups 5-6, $n=6$ and 8 , respectively.

the CSF should increase in response to the stimulus, and 2) the administration of indomethacin should alter the vascular response (3). However, the most intriguing question emerged from the present study: can all indomethacin-sensitive mechanisms safely be called COX-dependent? At least in the case of hypercapnia-induced pial arteriolar vasodilation this assumption appears to be false.

To address these issues, the present study used five structurally different COX inhibitors to elucidate the role of COX isoforms in selected pial arteriolar responses. The doses were carefully selected based on previous results in piglets or other species both for effective and selective COX inhibition. The dose of NS-398 was primarily chosen because it was found to be COX-2 selective and effectively preserved neuronalvascular function after hypoxic/ischemic stress in the piglet similarly to indomethacin (6). The plasma concentration of NS-398 reaching the pial endothelial cells following the IV bolus of $1 \mathrm{mg} / \mathrm{kg}$ dose is estimated at $30-50 \mu \mathrm{M}$, and this concentration range (from $10 \mu \mathrm{M}$ ) inhibited $\sim 70-90 \%$ of prostaglandin release in freshly isolated piglet cerebral microvascular endothelial cell cultures $(16,18)$. However, this dose (up to $100 \mu \mathrm{M}$ ) left prostaglandin production in human umbilical vein endothelial cells (HUVEC) intact, but HUVEC express only COX-1 (18). Based on these findings, in the piglet, the contribution of COX-1 to the endothelial/vascular prostanoid production has been expected to be minor (up to $10-20 \%)$. This remnant activity was targeted in the present study with SC-560. To the best of our knowledge, SC-560 has not been used in piglets previously. The dose was chosen since it was effective in blocking COX-1 activity in the rat brain even after COX-1 gene transfer (19), where brain prostaglandin production in COX-1 overexpressing transgenic mice could be successfully inhibited with this dose. Although SC-560 was without an effect in the present study, in adult mice pial application of $25 \mu \mathrm{M}$ SC-560 using cranial window resulted in about $50 \%$ decrease in hypercapnia-induced increase in cortical blood flow indicating a more prominent role of COX-1 in the adult mouse cerebral circulation (20). Ibuprofen and acetaminophen were used in a large pharmacological dose (30 $\mathrm{mg} / \mathrm{kg}$ ). This dose of ibuprofen can suppress cerebral COXactivity in piglets virtually $100 \%$ (21). Although acetaminophen is often enlisted as a nonsteroid anti-inflammatory drug, it is only a weak inhibitor of prostanoid biosynthesis except in the brain (22). This corresponds with its pronounced analgesic and antipyretic effects, and the lack of anti-inflammatory effect. Unlike the former studies, where $5 \mathrm{mg} / \mathrm{kg}$ indomethacin was used to diminish vasoreactivity to hypercapnia $(9,23)$, we used only $0.3-1 \mathrm{mg} / \mathrm{kg}$ to give a similar dose to the selective COX inhibitors. Indeed, in the present study NS-398 and indomethacin had the same potency to reduce hypotension-induced vasodilation or Ach-induced vasoconstriction, similarly to their neuroprotective effect in our previous study (6) or their antiinflammatory effects in a number of rat inflammation models $(24,25)$.

In the present study, we found a major discrepancy between the high efficacy of indomethacin and the failure of the COX-1 and COX-2 selective inhibitors to alter hypercapnia-induced vasodilation in piglets. In this species, hypercapnia-induced dilation of pial arterioles was impaired after light/dye endothelial injury, indicating endothelial involvement $(14,26)$. Additionally, vasodilation was found to be one of the numerous COX-dependent responses since inhibition of COX with indomethacin consistently abolished the vascular response $(9,27,28)$. The role of COX-derived prostanoids in the mechanism of vasodilation to hypercapnia has been proposed as a "permissive role" since supplementation of exogenous prostacyclin could restore arteriolar responsiveness following indomethacin or light-dye injury $(9,26)$. Interestingly, $\mathrm{PGE}_{2}$ also restored responsiveness after indomethacin, and adenosine as well as sodium nitroprusside were also partially effective (28).

Since COX-1 or COX-2 selective inhibitors could not mimic the conspicuous effect of indomethacin, we investigated whether the recently described acetaminophen-sensitive COX-3 isoform could be responsible for the production of prostanoids involved in this response (1). The occurrence of COX-3 isoform has not been investigated in the newborn piglet yet, but high COX-3 mRNA levels have been found in primary cerebrovascular endothelial cell cultures isolated from preterm rat fetuses (29). Thus, COX-3 may conceivably be present in the newborn cerebral blood vessels. However, its involvement in the hypercapnia-induced vasodilation is unlikely, since acetaminophen had no effect on the vascular response in the present study. Further, we also reassessed the effect of yet another structurally different nonselective COX inhibitor, ibuprofen on hypercapnia-induced pial vasodilation. Ibuprofen did not have any effect, confirming a previous study where ibu- 
profen inhibited increases in CSF prostaglandin levels during hypercapnia, but did not block arteriolar vasodilation (28). We extended these results by showing that after total COXinhibition by ibuprofen, $0.3 \mathrm{mg} / \mathrm{kg}$ indomethacin still did significantly reduce the cerebrovascular reactivity to hypercapnia. Our results therefore suggest that the remarkable efficacy of indomethacin to abolish arteriolar dilation to hypercapnia is probably unrelated to $\mathrm{COX}$-inhibition.

The inhibitory effect of indomethacin on hypercapniainduced vasodilation remains to be elusive, but is not due to nonspecific inhibition of VSM, since vasodilation to isoprenaline, substance $\mathrm{P}$, calcitonin gene-related peptide, and glutamate remain unchanged after $5 \mathrm{mg} / \mathrm{kg}$ indomethacin (30-32). Indomethacin has been suggested to inhibit prostacyclin receptors (33), and a 'double-blockade' effect both at the enzyme and receptor level may explain the conspicuous efficacy of indomethacin. Unfortunately, others found iloprost-induced vasodilation intact after indomethacin (8). Conceivably, indomethacin may interfere quite specifically with the yet unknown, enigmatic mechanism of hypercapnia-induced vasodilation. In the present study, two of the three indomethacinsensitive stimuli proved to be COX-dependent. We suggest that other indomethacin-sensitive vascular reactions should be reassessed with structurally different, preferably selective COX-inhibitors to identify the truly COX-dependent ones.

In conclusion, the use of selective COX-2 inhibitors as neuroprotective drugs in the neonate may be somewhat limited by their adverse effect on COX-dependent cerebrovascular control mechanisms. However, these vulnerable responses do not appear to include hypercapnia-induced vasodilation.

Acknowledgments. The authors gratefully acknowledge that NS-398 and indomethacin were gifts from Prof. David W. Busija. The authors thank Nancy Busija for the assistance in editing the manuscript.

\section{REFERENCES}

1. Chandrasekharan NV, Dai H, Roos KL, Evanson NK, Tomsik J, Elton TS, Simmons DL 2002 COX-3, a cyclooxygenase-1 variant inhibited by acetaminophen and other analgesic/antipyretic drugs: cloning, structure, and expression. Proc Natl Acad Sci USA 99:13926-13931

2. Domoki F, Veltkamp R, Thrikawala N, Robins G, Bari F, Louis TM, Busija DW 1999 Ischemia-reperfusion rapidly increases COX-2 expression in piglet cerebral arteries. Am J Physiol 277:H1207-H1214

3. Busija DW 1994 Cerebral circulation of the fetus and newborn. In: Bevan RD, Bevan JA (eds) The Human Brain Circulation. Humana Press, Clifton, pp 259-269

4. Armstead WM, Mirro R, Busija DW, Leffler CW 1988 Postischemic generation of superoxide anion by newborn pig brain. Am J Physiol 255:H401-H403

5. Pourcyrous M, Leffler CW, Mirro R, Busija DW 1990 Brain superoxide anion generation during asphyxia and reventilation in newborn pigs. Pediatr Res 28:618621

6. Domoki F, Perciaccante JV, Puskar M, Bari F, Busija DW 2001 Cyclooxygenase-2 inhibitor NS398 preserves neuronal function after hypoxia/ischemia in piglets. Neuroreport 12:4065-4068
7. Louis TM, Meng W, Bari F, Errico RA, Busija DW1996 Ischemia reduces CGRPinduced cerebral vascular dilation in piglets. Stroke 27:134-138; discussion 139

8. Bari F, Louis TM, Meng W, Busija DW1996 Global ischemia impairs ATP-sensitive $\mathrm{K}+$ channel function in cerebral arterioles in piglets. Stroke 27:1874-1880; discussion $1880-1881$

9. Leffler CW, Mirro R, Pharris LJ, Shibata M 1994 Permissive role of prostacyclin in cerebral vasodilation to hypercapnia in newborn pigs. Am J Physiol 267:H285-H291

10. Leffler CW, Busija DW 1987 Prostanoids and pial arteriolar diameter in hypotensive newborn pigs. Am J Physiol 252:H687-H691

11. Armstead WM, Mirro R, Busija DW, Leffler CW 1989 Permissive role of prostanoids in acetylcholine-induced cerebral vasoconstriction. J Pharmacol Exp Ther 251:1012_ 1019

12. Wagerle LC, Busija DW 1989 Cholinergic mechanisms in the cerebral circulation of the newborn piglet: effect of inhibitors of arachidonic acid metabolism. Circ Res 64:1030-1036

13. Peri KG, Hardy P, Li DY, Varma DR, Chemtob S 1995 Prostaglandin G/H synthase-2 is a major contributor of brain prostaglandins in the newborn. J Biol Chem 270:24615-24620

14. Leffler CW, Mirro R, Shanklin DR, Armstead WM, Shibata M 1994 Light/dye microvascular injury selectively eliminates hypercapnia-induced pial arteriolar dilation in newborn pigs. Am J Physiol 266:H623-H630

15. Eidson TH, Edrington JL, Albuquerque ML, Zuckerman SL, Leffler CW 1995 Light/dye microvascular injury eliminates pial arteriolar dilation in hypotensive piglets. Pediatr Res 37:10-14

16. Parfenova H, Eidson TH, Leffler CW 1997 Upregulation of COX-2 in cerebral microvascular endothelial cells by smooth muscle cell signals. Am J Physiol 273:C277-C288

17. Parfenova H, Levine V, Gunther WM, Pourcyrous M, Leffler CW 2002 COX-1 and COX-2 contributions to basal and IL-1 beta-stimulated prostanoid synthesis in human neonatal cerebral microvascular endothelial cells. Pediatr Res 52:342-348

18. Parfenova H, Balabanova L, Leffler CW 1998 Posttranslational regulation of cyclooxygenase by tyrosine phosphorylation in cerebral endothelial cells. Am J Physiol 274:C72-C81

19. Lin H, Lin TN, Cheung WM, Nian GM, Tseng PH, Chen SF, Chen JJ, Shyue SK, Liou JY, Wu CW, Wu KK 2002 Cyclooxygenase-1 and bicistronic cyclooxygenase$1 /$ prostacyclin synthase gene transfer protect against ischemic cerebral infarction. Circulation 105:1962-1969

20. Niwa K, Haensel C, Ross ME, Iadecola C 2001 Cyclooxygenase-1 participates in selected vasodilator responses of the cerebral circulation. Circ Res 88:600-608

21. Chemtob S, Beharry K, Barna T, Varma DR, Aranda JV 1991 Differences in the effects in the newborn piglet of various nonsteroidal antiinflammatory drugs on cerebral blood flow but not on cerebrovascular prostaglandins. Pediatr Res 30:106111

22. Flower RJ, Vane JR 1972 Inhibition of prostaglandin synthetase in brain explains the anti-pyretic activity of paracetamol (4-acetamidophenol). Nature 240:410-411

23. Wagerle LC, Mishra OP 1988 Mechanism of CO2 response in cerebral arteries of the newborn pig: role of phospholipase, cyclooxygenase, and lipoxygenase pathways. Circ Res 62:1019-1026

24. Futaki N, Yoshikawa K, Hamasaka Y, Arai I, Higuchi S, Iizuka H, Otomo S 1993 NS-398, a novel non-steroidal anti-inflammatory drug with potent analgesic and antipyretic effects, which causes minimal stomach lesions. Gen Pharmacol 24:105110

25. Futaki N, Takahashi S, Yokoyama M, Arai I, Higuchi S, Otomo S 1994 NS-398, a new anti-inflammatory agent, selectively inhibits prostaglandin $\mathrm{G} / \mathrm{H}$ synthase/ cyclooxygenase (COX-2) activity in vitro. Prostaglandins 47:55-59

26. Leffler CW, Fedinec AL, Shibata M1995 Prostacyclin receptor activation and pial arteriolar dilation after endothelial injury in piglets. Stroke 26:2103-2110; discussion $2110-2111$

27. Mirro R, Pharris LJ, Armstead WM, Shibata M, Leffler CW 1993 Effects of indomethacin on newborn pig pial arteriolar responses to PCO2. J Appl Physiol 75:1300-1305

28. Wagerle LC, Degiulio PA 1994 Indomethacin-sensitive CO2 reactivity of cerebral arterioles is restored by vasodilator prostaglandin. Am J Physiol 266:H1332-1338

29. Kis B, Snipes JA, Isse T, Nagy K, Busija DW 2003 Putative cyclooxygenase-3 expression in rat brain cells. J Cereb Blood Flow Metab 23:1287-1292

30. Busija DW, Chen J 1992 Effects of trigeminal neurotransmitters on piglet pial arterioles. J Dev Physiol 18:67-72

31. Busija DW, Leffler CW 1987 Eicosanoid synthesis elicited by norepinephrine in piglet parietal cortex. Brain Res 403:243-248

32. Busija DW, Leffler CW 1989 Dilator effects of amino acid neurotransmitters on piglet pial arterioles. Am J Physiol 257:H1200-H1203

33. Parfenova H, Zuckerman S, Leffler CW 1995 Inhibitory effect of indomethacin on prostacyclin receptor-mediated cerebral vascular responses. Am J Physiol 268:H1884-H1890 